\title{
RELAÇÃO DA INFRAESTRUTURA DA PROPRIEDADE E ALIMENTAÇÃO DOS ANIMAIS NA OCORRÊNCIA DE LEITE INSTÁVEL NÃO ÁCIDO NO PLANALTO NORTE DE SANTA CATARINA
}

\section{RELATIONSHIP BETWEEN FARM STRUCTURE AND ANIMAL FEED IN UNSTABLE NON-ACID MILK OCCURRENCE IN PLANALTO NORTE OF SANTA CATARINA}

\author{
Joana Gerent Voges ${ }^{1^{*}}$ \\ Nadine Cristina Felipus ${ }^{1}$ \\ Luan de Oliveira Canabarro ${ }^{2}$ \\ Deise Aline Knob ${ }^{1}$ \\ Daniele Cristina da Silva Kazama² \\ André Thaler Neto ${ }^{1}$ \\ ${ }^{1}$ Universidade do Estado de Santa Catarina, Florianópolis, SC, Brasil. \\ ${ }^{2}$ Universidade Federal de Santa Catarina, Florianópolis, SC, Brasil. \\ *Autora para correspondência - joanavoges@yahoo.com.br
}

\section{Resumo}

O teste do álcool é amplamente utilizado na recepção dos laticínios para a verificação da estabilidade do leite cru. O leite que não é estável no teste e não apresenta acidez elevada é definido como leite instável não ácido (LINA). A sua ocorrência tem característica multifatorial e pode estar relacionada ao manejo nutricional inadequado. Este estudo objetivou avaliar a influência da infraestrutura da propriedade e da alimentação dos animais sobre a ocorrência de LINA. A infraestrutura foi caracterizada através de questionário guia semiestruturado. Analisou-se a composição centesimal do leite das propriedades, resistência ao teste do álcool, acidez titulável e o pH. Foram consideradas LINA as amostras que precipitaram em concentração de álcool menor ou igual a $72 \%$, com acidez e pH normais. Nos alimentos coletados, determinou-se o teor de fibra em detergente neutro. Os dados foram avaliados através de análise fatorial e de agrupamento utilizando o pacote estatístico SAS. O uso de suplementos alimentares volumosos e concentrados, com consequente melhoria da produtividade animal e maior teor de lactose no leite foi relacionado com menor ocorrência de LINA nas condições estudadas. A ocorrência de LINA apresentou pouca relação com a infraestrutura das propriedades e com a estação do ano.

Palavras-chave: estabilidade do leite; produtividade; suplementação alimentar; teste do álcool

\footnotetext{
Abstract

The alcohol test is largely used in the dairy reception platform in order to verify raw milk stability. Milk that is not stable in the test and does not present high acidity is defined as unstable non-acid milk (UNAM). Its occurrence has a multifactorial characteristic and may be related to inadequate nutritional management. This study aimed to evaluate the influence of farm structure and animal feed
} 
on the occurrence of UNAM. The farm structure was characterized by means of a semi-structured questionnaire guide. Milk composition of the farms, resistance to alcohol test, titratable acidity and $\mathrm{pH}$ were analyzed. UNAM samples were those that precipitated at alcohol concentration less than or equal to $72 \%$, with normal acidity and $\mathrm{pH}$. Neutral detergent fiber was determined in the feed collected. Data were evaluated using factor and cluster analysis by using SAS statistical package. The use of roughages and concentrated food supplements with consequent improvement of animal productivity and higher lactose content in milk were associated with lower occurrence of UNAM under the studied conditions. The occurrence of UNAM had little relation with the farm structure and with the season of the year.

Keywords: alcohol test; feed supplementation; milk stability; productivity.

Recebido em: 24 de novembro de 2017

Aceito em: 22 de fevereiro de 2018

\section{Introdução}

A região do Planalto Norte de Santa Catarina tem como umas das principais atividades agrícolas o cultivo de fumo. Porém, a área plantada e, também, a produção de tabaco vêm diminuindo a cada ano na região, possivelmente devido às várias dificuldades atreladas a esse cultivo, enquanto a produção leiteira vem crescendo significativamente ${ }^{(1)}$. De 2010 a 2014, a Microrregião de Canoinhas, a mais expressiva da região, apresentou um crescimento em produção de mais de $63 \%$, com 79 milhões de litros de leite produzidos, $2,7 \%$ do total produzido no estado ${ }^{(1,2)}$

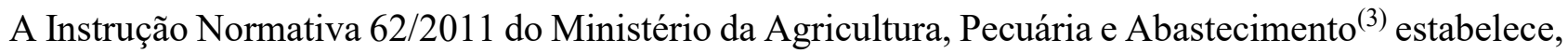
como parâmetros físico-químicos de qualidade do leite cru refrigerado, que este deve apresentar acidez titulável entre 0,14 e $0,18 \mathrm{~g}$ ácido lático/100 $\mathrm{mL}$ de leite. Também estabelece a obrigatoriedade da realização do teste do álcool antes da coleta de leite cru refrigerado, devendo apresentar estabilidade na concentração mínima de $72 \%(\mathrm{v} / \mathrm{v})$, sendo que o leite que precipita neste teste não deve ser coletado ${ }^{(3)}$.

O teste do álcool é amplamente utilizado nas plataformas de recepção dos laticínios visando à verificação da estabilidade térmica do leite cru. A prova avalia a estabilidade da caseína submetida à desidratação provocada pelo álcool simulando o tratamento térmico ${ }^{(4)}$. A caseína, proteína mais importante do leite bovino, é secretada em agrupamentos de várias moléculas de caseína ligadas a íons, como o fosfato de cálcio, formando as micelas de caseína. As principais frações dessa proteína são $\alpha s 1, \alpha s 2, \beta$ e $\kappa$-caseína e ocorrem numa proporção quantitativa de aproximadamente 4:1:4:1 ${ }^{(5-7)}$. A $\kappa$-caseína constitui a fração hidrofílica da micela de caseína, impedindo a agregação das micelas. Porém, quando, por algum motivo, há degradação dessa fração da caseína, ocorre a desestabilização das micelas, que coagulam ${ }^{(6,8,9)}$, podendo originar o leite instável não ácido (LINA).

O LINA apresenta perda da estabilidade da caseína quando submetido ao teste do álcool sem apresentar acidez elevada, ou seja, possui acidez titulável entre 0,14 e 0,18 g ácido lático/100 mL e pH entre 6,6 e $6,8^{(4,10)}$. O LINA não é desejado pela indústria, pois acredita-se que ele não resista ao processamento térmico, especialmente Ultra High Temperature (UHT), podendo comprometer o funcionamento e a limpeza dos equipamentos na indústria e provocar prejuízos à cadeia produtiva do leite ${ }^{(11-13)}$. 
A ocorrência de LINA tem característica multifatorial e a maior parte dos estudos realizados indica relação com o manejo nutricional inadequado ${ }^{(14-16)}$. O efeito da sazonalidade na frequência de LINA varia conforme a região do país e a produção de alimentos, estando sua ocorrência associada a períodos de baixa disponibilidade de pastos e de forragens de baixa qualidade, época em que há maiores chances de ocorrer restrição alimentar ${ }^{(4,17,18)}$. Assim, os componentes da dieta e o equilíbrio entre eles são importantes para manter a estabilidade do leite.

Outros fatores que podem influenciar na estabilidade do leite são a hidrólise enzimática da caseína por micro-organismos psicrotróficos proteolíticos, a alta contagem de células somáticas, o excesso de íons cálcio, a alteração no $\mathrm{pH}$ do leite, o desequilíbrio entre sais e, ainda, fatores que alteram o equilíbrio ácido-base de animais, tais como distúrbios gastrointestinais, distúrbios renais, dietas desequilibradas e o insucesso dos mecanismos fisiológicos compensatórios ${ }^{(17,19-22)}$.

Considerando a característica multifatorial da ocorrência de LINA, o uso de técnicas multivariadas é conveniente para examinar os fatores envolvidos, uma vez que as análises convencionais podem capturar o efeito de apenas um ou dois fatores. Assim, o presente estudo objetivou avaliar a influência conjunta da alimentação dos animais e da infraestrutura das propriedades leiteiras sobre a ocorrência de LINA na região do Planalto Norte de Santa Catarina.

\section{Material e Métodos}

A pesquisa foi desenvolvida em propriedades de cooperados de três cooperativas de leite da agricultura familiar dos municípios de Major Vieira, Papanduva e Monte Castelo, na região do Planalto Norte de Santa Catarina. Foram avaliadas 66 propriedades leiteiras no inverno e 69 no verão, resultando um total de 135 amostras analisadas, sendo que as diferenças no número de propriedades de uma coleta para a outra se devem à entrada de produtores nas cooperativas.

As propriedades participantes foram visitadas duas vezes, uma no inverno (julho de 2013) e outra no verão (fevereiro de 2014). Em cada visita foram coletadas amostras de leite diretamente dos tanques resfriadores e do alimento fornecido aos animais, incluindo pastagens, silagens e alimentos concentrados. Nas duas estações, as propriedades foram caracterizadas por meio de um questionário guia semiestruturado, aprovado no Comitê de Ética em Pesquisas com Seres Humanos da Universidade Federal de Santa Catarina com Certificado de Apresentação para Apreciação Ética (CAAE) n ${ }^{\circ}$ 12185013.6.0000.0121, abordando manejo alimentar e caracterização da propriedade e da produção leiteira por perguntas objetivas direcionadas ao produtor ou por visualização do entrevistador, principalmente quando relativas às instalações e equipamentos.

O leite foi homogeneizado antes de cada coleta ligando a agitação do tanque de expansão por cinco minutos ou, no caso de refrigeradores de imersão, utilizando um agitador manual para homogeneizar os tarros por, pelo menos, dez segundos ${ }^{(23)}$. A coleta do leite foi feita com concha coletora de aço inoxidável, flambada com álcool 96\%, imediatamente antes de cada coleta. No caso de refrigeradores de imersão, com mais de um tarro, foram coletados números iguais de amostras de cada tarro que foram misturadas em um recipiente de aço inoxidável para depois uma amostra composta ser acondicionada nos frascos de coleta. Os frascos, de $100 \mathrm{~mL}$, foram identificados e colocados em caixa isotérmica com gelo reciclável para mantê-los em temperatura máxima de $7^{\circ} \mathrm{C}$. Em seguida, as caixas 
foram encaminhadas ao Laboratório de Análise de Alimentos da Universidade do Contestado Campus Canoinhas, Marcílio Dias (na coleta de verão) ou ao Laboratório de Microbiologia de Alimentos do Instituto Federal de Santa Catarina - Campus Canoinhas (na coleta de inverno).

Em cada propriedade, foram coletadas duas amostras de leite: uma para composição (gordura, lactose, proteína, nitrogênio ureico no leite (NUL) e caseína) e outra para a realização das análises físicoquímicas do leite (teste do álcool, acidez titulável e pH).

As amostras de leite para análise de gordura, lactose, proteína, NUL e caseína foram acondicionadas em frascos-padrão para coleta contendo o conservante bronopol. As amostras foram analisadas por leitura de absorção infravermelha (equipamento BENTLEY - 2000) ${ }^{(24)}$ pelo Laboratório do Programa de Análises do Rebanho Leiteiro (PARL) da Associação Paranaense de Criadores de Bovinos da Raça Holandesa (APCBRH) em Curitiba-PR, participante da Rede Brasileira de Qualidade do leite.

No teste de estabilidade do leite ao álcool foi avaliada a concentração de álcool etílico em que ocorre a precipitação do leite. Para tal, foram pipetadas soluções alcoólicas crescentes de 58 a $80 \%$ (v/v), com intervalos de 2\% em uma placa de Petri com o mesmo volume de leite e, após homogeneização, foi avaliada a presença de grumos na placa. Foram consideradas como leite instável não ácido (LINA) as amostras de leite que precipitaram em concentração de álcool menor ou igual a $72 \%$, com acidez e pH normais (entre 14 e $18^{\circ} \mathrm{D}$ e entre 6,6 e 6,8 , respectivamente) ${ }^{(3)}$. A determinação da acidez titulável foi feita através do teste de Dornic descrito pela $\mathrm{IN} 68^{(25)}$ e o $\mathrm{pH}$ do leite foi medido com um pHmetro portátil (Sanxin SX711) $)^{(25)}$.

As amostras de alimentos secos foram acondicionadas em sacos plásticos e levadas ao laboratório. As amostras de alimentos úmidos foram acondicionadas em caixas de isopor em temperatura em torno de $7{ }^{\circ} \mathrm{C}$ e levadas ao laboratório. As amostras de pastagens foram coletadas por meio da técnica do quadrado de $0,25 \mathrm{~m}^{2(26)}$ lançado nos piquetes em que as vacas se encontravam, sendo cinco pontos coletados em cada piquete. O pasto foi cortado rente ao solo em toda a área do quadrado, pesado e acondicionado em sacos de papel para transporte até o laboratório.

As silagens, pastagens e demais alimentos úmidos foram pré-secos em estufa com ventilação forçada a $55{ }^{\circ} \mathrm{C}$ por 72 horas e, posteriormente, assim como os alimentos secos, moídos com peneiras com crivos de $1 \mathrm{~mm}$ e acondicionados em potes plásticos em freezer $-20{ }^{\circ} \mathrm{C}$ para posteriores análises químicas no Laboratório de Nutrição Animal do Departamento de Zootecnia e Desenvolvimento Rural da Universidade Federal de Santa Catarina. A determinação do teor de fibra em detergente neutro (FDN) foi realizada de acordo com Van Soest et al. ${ }^{(27)}$.

Os dados foram avaliados por análise multivariada fatorial e de agrupamento, usando o pacote estatístico SAS® versão 9.2, e previamente padronizados pelo procedimento STANDARD. A análise fatorial foi realizada pelo procedimento FACTOR, considerando dois fatores e a rotação da matriz Promax. Para a análise de agrupamento, foram utilizados os procedimentos FASTCLUS, DISCRIM e CLUSTER, empregando-se o método de Ward, baseado na distância Euclidiana. A comparação entre os grupos formados foi realizada por análise multivariada de variância (MANOVA), utilizando o procedimento GLM, sendo as médias dos grupos comparadas pelo teste Tukey-Kramer, ao nível de significância de 5\%.

A infraestrutura das propriedades foi caracterizada pelas seguintes variáveis: estrutura da sala de ordenha (estrutura de madeira, de alvenaria sem azulejo e de alvenaria com azulejo), tipo de ordenha (ordenha manual, equipamento mecanizado balde ao pé e totalmente mecanizado) e número de 
animais. A produção de leite/vaca/dia foi utilizada como indicador da especialização em produção leiteira. A alimentação das vacas foi caracterizada pelo tipo de concentrado fornecido (não suplementa, suplementa só com energético e suplementa com energético e proteico), pela quantidade de suplementação volumosa e pelo FDN da pastagem. Por fim, para descrever a qualidade do leite foram selecionadas as variáveis: concentração de álcool em que ocorre a precipitação do leite, ocorrência de LINA e teores de gordura, caseína, lactose e NUL. Para fins estatísticos, algumas variáveis foram divididas em classes com intuito de auxiliar na análise dos resultados. A variável produção de leite/vaca/dia foi dividida em: até $10 \mathrm{~L}$, de 10 a $15 \mathrm{~L}$ e acima de $15 \mathrm{~L}$; e a quantidade de volumoso em: não suplementa, até $15 \mathrm{~kg} /$ dia e acima de $15 \mathrm{~kg} /$ dia.

\section{Resultados e Discussão}

As estações inverno e verão foram bem definidas na região durante a execução do trabalho, com temperatura média de $8,3{ }^{\circ} \mathrm{C}$ e amplitude térmica de $3,9^{\circ} \mathrm{C}$ a $13,8{ }^{\circ} \mathrm{C}$ no inverno e temperatura média de $23,7^{\circ} \mathrm{C}$ com amplitude de $17,2^{\circ} \mathrm{C}$ a $31,8{ }^{\circ} \mathrm{C}$ no verão. A precipitação pluviométrica média diária foi de $9,5 \mathrm{~mm}$ no inverno e de $1,1 \mathrm{~mm}$ no verão (dados meteorológicos disponibilizados pela EPAGRI/CIRAM).

As propriedades possuíam em média oito vacas em lactação, variando de uma a 50, com produção média diária de 105 litros, variando de 5 a 1100 litros de leite. A área média das propriedades era de 25 ha, variando de 5 a 145 ha. Os animais eram, em sua maioria, mestiços Jersey e Holandês, porém havia também vacas mestiças com Gir e Pardo Suíço. O tempo em que os produtores envolvidos no estudo trabalhavam na atividade leiteira variava de um a 35 anos, com média de 10 anos na atividade.

As propriedades participantes apresentavam, em média, um pequeno número de vacas e baixa produção de leite/vaca/dia (Tabela 1), um indicativo de pequenas unidades produtoras, com baixo nível de tecnificação. Poucas propriedades utilizavam a suplementação volumosa (geralmente silagem de milho) além das pastagens e a utilização de suplementação concentrada era variada, com média de $3,34 \mathrm{~kg} / \mathrm{vaca} / \mathrm{dia}$, o que pode ajudar a explicar a baixa produtividade leiteira. A qualidade das pastagens se mostrou bem variada, com uma média de 46,93\% de FDN. A FDN é uma medida do conteúdo total de fibra insolúvel do alimento que interfere na qualidade da dieta e no consumo, visto que dietas a base de volumosos têm geralmente baixa densidade energética e o consumo poderá ser limitado, por exemplo, pelo efeito do enchimento ruminal ${ }^{(28)}$. Segundo Moreira et al. ${ }^{(29)}$, existe uma relação inversa entre o conteúdo de fibras dos alimentos e o seu valor energético, sendo inverso também ao consumo voluntário dos animais, porém ele é essencial para o funcionamento normal do rúmen e o aporte de energia. Do total de amostras analisadas, $25 \%$ eram de LINA, sendo que, em média, a precipitação do leite no teste do álcool ocorreu em concentração alcoólica de 73,06\% (Tabela $1)$. 
Tabela 1. Estatistica descritiva das variáveis utilizadas nas análises fatoriais

\begin{tabular}{|c|c|c|c|c|c|c|}
\hline \multirow{4}{*}{$\begin{array}{r}\text { Grupo } \\
\text { Estrutura da } \\
\text { propriedade }\end{array}$} & \multirow{4}{*}{$\begin{array}{c}\text { Variável } \\
\text { Número de vacas } \\
\text { Estrutura sala ordenha } \\
\text { Tipo ordenha }{ }^{2}\end{array}$} & \multicolumn{3}{|c|}{ Média \pm DP } & \multirow{2}{*}{$\begin{array}{c}\text { Mínimo } \\
2,00\end{array}$} & \multirow{2}{*}{$\frac{\text { Máximo }}{60,00}$} \\
\hline & & 11,71 & \pm & 7,66 & & \\
\hline & & 0,20 & \pm & 0,51 & 0,00 & 2,00 \\
\hline & & 2,01 & \pm & 0,40 & 1,00 & 3,00 \\
\hline \multirow{2}{*}{ Produtividade } & $\mathrm{L} /$ vaca/dia & 12,03 & \pm & 4,67 & 2,50 & 27,50 \\
\hline & Classes $^{3}$ & 1,97 & \pm & 0,78 & 1,00 & 3,00 \\
\hline \multirow{4}{*}{$\begin{array}{l}\text { Alimentação das } \\
\text { vacas }\end{array}$} & Concentrado (kg/vaca/dia) & 3,34 & \pm & 2,54 & 0,00 & 14,40 \\
\hline & Tipo de concentrado 4 & 1,47 & \pm & 0,64 & 0,00 & 2,00 \\
\hline & Suplementação volumosa ${ }^{5}$ & 0,34 & \pm & 0,69 & 0,00 & 2,00 \\
\hline & FDN da pastagem $(\%)^{6}$ & 46,93 & \pm & 9,90 & 25,69 & 63,33 \\
\hline \multirow{6}{*}{ Qualidade do leite } & Concentr. âlcool $\left({ }^{\circ} \mathrm{GL}\right)^{7}$ & 73,06 & \pm & 5,16 & 58,00 & 80,00 \\
\hline & Ocorrência de LINA ${ }^{8}(\%)$ & 25,00 & \pm & - & - & - \\
\hline & Gordura (\%) & 3,88 & \pm & 0,47 & 2,64 & 5,10 \\
\hline & Caseina (\%) & 2,49 & \pm & 0,22 & 1,79 & 3,13 \\
\hline & Lactose (\%) & 4,46 & \pm & 0,18 & 3,59 & 4,81 \\
\hline & $\mathrm{NUL}(\mathrm{mg} / \mathrm{dL})^{9}$ & 12,77 & \pm & 4,27 & 3,26 & 26,42 \\
\hline
\end{tabular}

${ }^{2} 0=$ estrutura de madeira, 1 = estrutura de alvenaria sem azulejo e 2 = estrutura de alvenaria com azulejo.

${ }^{2} 1$ = ordenha manual, 2 = equipamento mecanizado balde ao pé e 3 = equipamento totalmente mecanizado.

'1 = até $10 \mathrm{~L}, 2$ = de 10 a $15 \mathrm{~L}$ e 3 = acima de $15 \mathrm{~L}$.

${ }^{4} 0$ = não suplementa, 1 = suplementa só com energético e 2 = suplementa com energético e proteico.

${ }^{5} 0$ = não suplementa, 1 = até $15 \mathrm{~kg} /$ dia e 2 = acima de $15 \mathrm{~kg} /$ dia.

${ }^{6}$ Fibra em detergente neutro da pastagem.

${ }^{7}$ Graduação alcoólica em que ocorreu a precipitação do leite no teste do álcool.

sLeite instável não ácido.

Nitrogênio ureico do leite.

A ocorrência de LINA é menor ou próxima à relatada em outros estudos do país, como o de Battaglini et al. ${ }^{(17)}$, que relataram que, das 353 amostras de leite coletadas diretamente de resfriadores em seis municípios da microrregião de Ivaiporã e Sapopema-PR, 43,6\% eram LINA. Das 334 amostras de leite a granel coletadas de fazendas que forneciam leite para um laticínio localizado no nordeste do estado de São Paulo no outono, inverno e primavera, $23 \%$ foram instáveis ao álcool $72 \%{ }^{(30)}$. Ao verificar a qualidade do leite armazenado nos silos para leite cru de uma usina de beneficiamento da região metropolitana da Porto Alegre-RS nos meses de agosto e setembro de 2008, Ciprandi et al. ${ }^{(31)}$ classificaram 34\% das 92 amostras coletadas como LINA. Em um estudo realizado em 51 propriedades leiteiras da região do Vale do Braço do Norte-SC, a ocorrência de LINA foi de $29 \%{ }^{(32)}$.

Em uma primeira análise fatorial foi relacionada à ocorrência de LINA com a infraestrutura da propriedade, sendo que a soma dos dois primeiros fatores explicou 58,48\% da variação total (Tabela 2). $\mathrm{O}$ fator 1 representa a relação positiva entre as variáveis de estrutura da propriedade (número de vacas, estrutura da sala de ordenha e tipo de ordenha), demonstrada pela igualdade de suas cargas fatorais. $\mathrm{O}$ fator 2 representa a relação inversa entre a produção de leite/vaca/dia nas diferentes propriedades e a ocorrência de LINA, demonstrada pela oposição de suas cargas fatorais. As elevadas comunalidades demonstraram a alta relevância de cada variável utilizada nesta análise e a importância destas para o estudo. 
Tabela 2. Cargas fatoriais, comunalidades e percentual de variância das variáveis utilizadas para a análise fatorial que relaciona ocorrência de LINA com a estrutura da propriedade

\begin{tabular}{|c|c|c|c|}
\hline \multirow{2}{*}{ Variáveis } & \multicolumn{2}{|c|}{ Fatores } & \multirow{2}{*}{ Comunalidade } \\
\hline & Fator 1 & Fator 2 & \\
\hline Número de vacas & 0,7616 & $-0,0493$ & 59,29 \\
\hline Estrutura sala ordenha ${ }^{1}$ & 0,7321 & 0,1555 & 52,85 \\
\hline Tipo ordenha ${ }^{2}$ & 0,7289 & $-0,1438$ & 58,11 \\
\hline Ocorrência de LINA ${ }^{3}$ & 0,1012 & 0,9245 & 83,90 \\
\hline Produção/vaca/dia ${ }^{4}$ & 0,3574 & $-0,4577$ & 38,25 \\
\hline \% Variância & 38,21 & 20,27 & \\
\hline
\end{tabular}

$\mathrm{O}$ primeiro fator indica que as propriedades com menos animais apresentam menores investimentos em estrutura e tecnologia, assim como as propriedades maiores podem investir mais nesses pontos. Ao avaliar a eficiência produtiva das propriedades leiteiras, Nero et al. ${ }^{(33)}$ também constataram que a maioria dos produtores tinha pequena quantidade de animais em lactação, baixa produção e produtividade por vaca. Por outro lado, as variáveis relacionadas à infraestrutura da propriedade não apresentaram relação com a ocorrência de LINA, a qual, por sua vez, apresentou relação negativa à produção de leite/vaca/dia (fator 2), indicando que propriedades com animais menos produtivos apresentam maior ocorrência de LINA. Isso pode estar relacionado aos fatores nutricionais, já que a subnutrição pode aumentar a apoptose das células epiteliais mamárias e reduzir a capacidade produtiva dos animais, modificar a composição e o pH sanguíneos, causando mudanças na composição do leite relacionadas à sua capacidade de resistir à desidratação alcoólica ${ }^{(15)}$.

Em uma segunda análise fatorial foram avaliadas as relações entre a ocorrência de LINA, a alimentação dos animais e a composição do leite, sendo que a soma dos dois primeiros fatores explicou 42,98\% da variação total (Tabela 3 ). No fator 1, as variáveis com maior carga fatorial foram estação do ano e teor de FDN da pastagem e, com representatividade um pouco menor, o teor de nitrogênio ureico no leite (NUL), suplementação volumosa e teor de lactose. No fator 2, as variáveis com maior carga fatorial foram os teores de gordura e caseína, a suplementação com concentrado, a produtividade e ocorrência de LINA.

A relação entre as variáveis do fator 1 mostra que, no verão, as pastagens apresentaram maior teor de FDN. O FDN elevado é característico das forragens tropicais e, segundo Gerdes et al. ${ }^{(34)}$, em algumas espécies os teores aumentam ainda mais no verão devido à rápida elongação da haste das gramíneas nesta época. As características dos alimentos volumosos disponíveis nessa época do ano (pastagem mais fibrosa e menor utilização de forragem conservada) apresentaram relação com menores teores de lactose no leite. A concentração de lactose no leite cru é influenciada por múltiplos fatores como a contagem de células somáticas, a ordem de parição e a estação do ano, devido à variação sazonal na qualidade e na quantidade de alimentos. Uma deficiência nutricional acarretada por redução qualiquantitativa de volumosos em algumas épocas do ano pode representar diminuição significativa nos teores de lactose no leite ${ }^{(35)}$. A carga fatorial negativa para nitrogênio ureico do leite (NUL) significa que os teores foram mais elevados no inverno. Nessa estação, a presença de pastagens com maior teor de proteína bruta, como aveia (Avena spp.) e azevém (Lolium multiflorum), pode ter influenciado no maior teor de NUL, assim como pode ter influência a falta de sincronização entre as taxas de degradação de carboidratos e proteínas, com consequente baixa produção de proteína microbiana ${ }^{(36)}$. 
Tabela 3. Cargas fatoriais, comunalidades e percentual de variância das variáveis utilizadas para a análise fatorial que relaciona ocorrência de LINA com alimentação dos animais e composição do leite

\begin{tabular}{|c|c|c|c|}
\hline \multirow{2}{*}{ Variáveis } & \multicolumn{2}{|c|}{ Fatores } & \multirow{2}{*}{ Comunalidades } \\
\hline & Fator 1 & Fator 2 & \\
\hline Teor de FDN da pastagem 1 & 0,8660 & 0,1474 & 73,75 \\
\hline Estação do ano ${ }^{2}$ & 0,8589 & $-0,1525$ & 79,59 \\
\hline Teor de lactose & $-0,3373$ & $-0,2903$ & 17,18 \\
\hline $\mathrm{NUL}^{3}$ & $-0,4949$ & $-0,4036$ & 35,44 \\
\hline Suplementação volumosa ${ }^{4}$ & $-0,5582$ & 0,1770 & 36,93 \\
\hline Teor de gordura & 0,0524 & 0,7287 & 52,36 \\
\hline Teor de caseina & $-0,2610$ & 0,5396 & 39,70 \\
\hline Ocorrência de LINA ${ }^{5}$ & 0,1205 & 0,4420 & 19,57 \\
\hline Produção/vaca/ $\mathrm{dia}^{6}$ & $-0,1291$ & $-0,5608$ & 31,18 \\
\hline Suplementação concentrada? & 0,2249 & $-0,5936$ & 43,86 \\
\hline \% Variância & 24,01 & 18,95 & \\
\hline
\end{tabular}

'Fibra em detergente neutro da pastagem.

${ }^{2} 1$ = inverno e 2 = verão.

${ }^{3}$ Nitrogênio ureico do leite.

${ }^{4} 0$ = não suplementa, 1 = até $15 \mathrm{~kg} / \mathrm{vaca} /$ dia e 2 = acima de $15 \mathrm{~kg} / \mathrm{vaca} / \mathrm{dia}$.

'Leite instável não ácido.

${ }^{\circ} 1$ = até $10 \mathrm{~L}, 2=$ de 10 a $15 \mathrm{~L}$ e $3=$ acima de $15 \mathrm{~L}$.

${ }^{7} 0$ = não suplementa, 1 = suplementação somente energética e 2 = suplementação energética e proteica.

No fator 2, a maior produção de leite está relacionada a menores teores de sólidos do leite, como a gordura e a caseína, e vice-versa. Dietas com maior suplementação concentrada e, consequentemente maior teor de energia estão relacionadas à maior produção e estabilidade do leite ao teste do álcool, com redução de $\operatorname{LINA}^{(37)}$, que, por sua vez, estão relacionadas negativamente aos teores de gordura e caseína. Isso pode estar relacionado à menor produção de leite/vaca/dia nas condições de menor oferta alimentar, o que reduz a produção leiteira, aumentando os teores de proteína e gordura, enquanto o teor de lactose não apresenta relação com a produção ${ }^{(35)}$. Essa maior produção de leite/vaca/dia foi obtida, na sua maioria, em propriedades que utilizavam suplementação concentrada, principalmente energética e proteica, a qual, por sua vez, estava associada às amostras de leite estável, com menor ocorrência de LINA. Estando a ocorrência de LINA associada à baixa produção e suplementação somente energética. Marques et al. ${ }^{(15)}$ mostram que os animais que receberam suplementação concentrada com melhor balanço nos níveis de energia e proteína produziram leite mais estável.

Foram formados três grupos distintos na análise de agrupamento pelas variáveis estrutura da sala ordenha, tipo de ordenha, número de vacas, produção/vaca/dia, suplementação volumosa, teor de FDN da pastagem, ocorrência de LINA e teores de caseína, lactose e gordura (Tabela 4). De acordo com essa análise, existem dois grupos com baixa prevalência de LINA (grupos 2 e 3). Desses, o grupo 2, com apenas cinco observações, é formado pelos maiores produtores com características distintas dos demais, que possuíam melhor estrutura de sala de ordenha, equipamento de ordenha mecanizado, maior número de vacas e maior produção/vaca/dia. Essas propriedades possuíam forragens com menor FDN, o que indica a melhor qualidade das pastagens. Propriedades leiteiras com produção em escala maior utilizam maior quantidade de alimentos de melhor qualidade, apresentam nível tecnológico produtivo superior e, provavelmente, um melhor desempenho de ordenha e manejo sanitário, com efeitos positivos sobre a produção e composição do leite ${ }^{(38-40)}$. O menor teor de sólidos no leite do grupo 2 é provavelmente efeito da diluição desses componentes, visto que esse grupo se 
difere dos demais pela maior produção.

Tabela 4. Grupos formados pela análise de agrupamento das variáveis que relacionam ocorrência de LINA com alimentação dos animais e composição do leite

\begin{tabular}{ccccc}
\hline Variáveis & Grupo 1 & Grupo 2 & Grupo 3 & P \\
\hline Estrutura sala ordenha $^{1}$ & $0,17 \mathrm{~b}$ & $1,25 \mathrm{a}$ & $0,16 \mathrm{~b}$ & $<0,0001$ \\
Tipo ordenha $^{2}$ & $1,86 \mathrm{c}$ & $2,75 \mathrm{a}$ & $2,14 \mathrm{~b}$ & $<0,0001$ \\
Número de vacas $^{2}$ & $10,91 \mathrm{~b}$ & $60,19 \mathrm{a}$ & $11,01 \mathrm{~b}$ & $<0,0001$ \\
Produção/vaca/dia $^{3}$ & $1,89 \mathrm{~b}$ & $3,00 \mathrm{a}$ & $2,02 \mathrm{~b}$ & $=0,0163$ \\
Suplementação volumosa $^{4}$ & $0,13 \mathrm{~b}$ & $1,01 \mathrm{a}$ & $0,65 \mathrm{a}$ & $<0,0001$ \\
Tipo concentrado $^{5}$ & 1,44 & 2,00 & 1,47 & $=0,3313$ \\
FDN da pastagem (\%) $^{6}$ & $48,82 \mathrm{a}$ & $40,12 \mathrm{~b}$ & $44,17 \mathrm{~b}$ & $=0,0279$ \\
Ocorrência LINA $^{7}$ & $0,37 \mathrm{a}$ & $0,00 \mathrm{~b}$ & $0,09 \mathrm{~b}$ & $<0,0007$ \\
Caseína $(\%)^{\text {Lactose }(\%)}$ & $2,42 \mathrm{~b}$ & $2,28 \mathrm{~b}$ & $2,62 \mathrm{a}$ & $<0,0001$ \\
Gordura (\%) & $4,38 \mathrm{~b}$ & $4,51 \mathrm{ab}$ & $4,60 \mathrm{a}$ & $<0,0001$ \\
NUL $(\mathrm{mg} / \mathrm{dL})^{8}$ & $3,80 \mathrm{~b}$ & $3,34 \mathrm{~b}$ & $4,22 \mathrm{a}$ & $<0,0001$ \\
\hline
\end{tabular}

Número de observações

84

0 = estrutura de madeira, 1 = estrutura de alvenaria sem azulejo e 2 = estrutura de alvenaria com azulejo.

${ }^{2} 1$ = ordenha manual, 2 = equipamento mecanizado balde ao pé e 3 = equipamento totalmente mecanizado.

' 1 = até $10 \mathrm{~L}, 2=$ de 10 a $15 \mathrm{~L}$ e $3=$ acima de $15 \mathrm{~L}$.

${ }^{4} 0$ = não suplementa, 1 = até $15 \mathrm{~kg} /$ dia e $2=$ acima de $15 \mathrm{~kg} /$ dia.

${ }^{5} 0=$ não suplementa, 1 = suplementa só com energético e 2 = suplementa com energético e proteico.

${ }^{6}$ Fibra em detergente neutro da pastagem.

'Leite instável não ácido.

Sitrogênio ureico do leite.

Os grupos 1 e 3, formados por propriedades menores e com infraestrutura de produção mais modesta, distinguem-se pela ocorrência de LINA, sendo que o primeiro apresentou ocorrência em $37 \%$ das propriedades contra $9 \%$ no grupo 3 . Esses grupos não diferiram quanto à estrutura de ordenha, número de vacas e produção/vaca/dia, porém o grupo 1 possuía menor tecnificação do equipamento de ordenha. Embora a análise fatorial não tenha apresentado relação direta entre a ocorrência de LINA e a estrutura da propriedade (Tabela 2), a análise de agrupamento demostrou que as condições relacionadas à maior instabilidade do leite são mais comuns em propriedades com ordenha menos tecnificadas.

Em relação ao grupo 1, o grupo 3, que apresenta menor ocorrência de LINA, é o que mais utiliza suplementação volumosa na alimentação dos animais, além de ter pastagens de melhor qualidade, indicado pelo menor teor de FDN. O grupo 3 tinha também maior teor de caseína, lactose e gordura no leite produzido. Isso pode estar associado a um melhor manejo nutricional, manutenção da qualidade e da constância dos alimentos durante o ano ${ }^{(14)}$. Estratégias de alimentação envolvendo o uso de silagem, suplementos vitamínicos e minerais, calcário, sal e disponibilidade de pasto relacionam-se positivamente com a concentração de lactose, sendo essas estratégias principalmente utilizadas por propriedades com maior número de vacas e maior produtividade ${ }^{(39)}$. Oliveira et al. ${ }^{(29)}$ verificaram que o leite estável apresenta maiores teores de caseína e lactose que o instável. A porcentagem mais elevada de caseína deve-se possivelmente ao maior aporte de nutrientes e aos maiores teores de proteína nos alimentos fornecidos ${ }^{(14)}$. 


\section{Conclusão}

O uso de suplementos alimentares volumosos e concentrados, com consequente melhoria da produtividade animal e maior teor de lactose no leite estão relacionados com a menor ocorrência de LINA nas condições das propriedades de agricultura familiar do Planalto Norte de Santa Catarina. A ocorrência de LINA apresenta pouca relação com a infraestrutura das propriedades e com a estação do ano.

\section{Agradecimentos}

À Fundação de Amparo à Pesquisa e Inovação de Santa Catarina (FAPESC) pelo financiamento do estudo. Aos produtores rurais das cooperativas CAFLEMAV, COAFAPA e COOPERLEITE pela colaboração no estudo e pelo propósito de se aperfeiçoarem a partir dos resultados da pesquisa. Ao Laboratório de Análise de Alimentos da Universidade do Contestado - Campus Canoinhas, Marcílio Dias e ao Laboratório de Microbiologia de Alimentos do Instituto Federal de Santa Catarina Campus Canoinhas, pela disponibilização da estrutura para realização das análises laboratoriais durante o período de coletas.

\section{Referências}

1. EPAGRI/CEPA. Síntese Anual da Agricultura de Santa Catarina 2015-2016. Florianópolis: Epagri/Cepa, 2016 [acesso em 29 de março de 2017]. Disponível em: http://docweb.epagri.sc.gov.br/website_cepa/publicacoes/Sintese_2016.pdf.

2. IBGE. Produção Pecuária Municipal 2014. Rio de Janeiro: IBGE, 2015[acesso em 29 de março de 2017]. Disponível

em: ftp://ftp.ibge.gov.br/Producao_Pecuaria/Producao_da_Pecuaria_Municipal/2012/ppm2012.pdf.

3. Brasil. Ministério da Agricultura, Pecuária e Abastecimento. Instrução Normativa $n^{\circ} 62$, de 29 de dezembro de 2011. Diário Oficial da União. 2011 Dez 30; Seção 1. Português.

4. Oliveira CAFD, Lopes LC, Franco RC, Corassin CH. Composição e características físico-químicas do leite instável não ácido recebido em laticínio do Estado de São Paulo, Brasil. Revista Brasileira de Saúde e Produção Animal [Internet]. 2011 Abr/jun [citado 29 jun 2015]; 12(2): 508-515. Disponível em: http://www.rbspa.ufba.br/index.php/rbspa/article/view/1909/1119. Português.

5. Farrell HM, Malin EL, Brown EM, Qi PX. Casein micelle structure: What can be learned from milk synthesis and structural biology? Current Opinion in Colloid \& Interface Science [Internet]. 2006 Jun [citado 29 jun 2015]; 11(2): 135-147. Disponível em: https://doi.org/10.1016/j.cocis.2005.11.005. Inglês.

6. Fox PF, Brodkorb A. The casein micelle: historical aspects, current concepts and significance. International Dairy Journal [Internet]. 2008 Jul [citado 29 jun 2015]; 18(7): 677-684. Disponível em: https://doi.org/10.1016/j.idairyj.2008.03.002. Inglês.

7. Bonizzi I, Buffoni JN, Feligini M. Quantification of bovine casein fractions by direct chromatographic analysis of milk. Approaching the application to a real production context. Journal of Chromatography A [Internet]. 2009 Jan [citado 29 jun 2015]; 1216(1):165-168. Disponível em: https://doi.org/10.1016/j.chroma.2008.11.045. Inglês.

8. Hidalgo ME, Pires MS, Risso PH. A study on bovine kappa-casein aggregation after the enzymatic action 
of chymosin. Colloids and Surfaces B: Biointerfaces [Internet]. 2010 Abr [citado 29 jun 2015]; 76(2): 556563. Disponível em: https://doi.org/10.1016/j.colsurfb.2009.12.018. Inglês.

9. Kruif CG, Huppertz T, Urban VS, Petukhov AV. Casein micelles and their internal structure. Advances in Colloid and Interface Science [Internet]. 2012 Mar/abr [citado 29 jun 2015]; 171(1): 36-52. Disponível em: https://doi.org/10.1016/j.cis.2012.01.002. Inglês.

10. Fischer V, Zanela MB, Ribeiro MER, Marques LT, Stumpf Junior W, Vidal LEB. Prevalência, indução e tratamento do leite instável não ácido (LINA) no sul do Brasil. In: Qualidade do leite bovino: variações no trópico e no subtrópico. Diaz González F, Pinto AT, Zanela MB, Fischer V, Bondan C. (Org.). Passo Fundo: Ed. Universidade de Passo Fundo; 2011. p. 141-160. Português.

11. Marques LT, Zanela MB, Ribeiro MER, Stumpf Júnior W, Fischer V. Ocorrência do leite instável ao álcool $76 \%$ e não ácido (LINA) e efeito sobre os aspectos físico-químicos do leite. Revista Brasileira de Agrociência [Internet]. 2007 Jan/mar [citado 29 jun 2015]; 13(1): 91-97. Disponível em: https://www.periodicos.ufpel.edu.br/ojs2/index.php/CAST/article/view/1343/1127. Português.

12. Domareski JL, Bandiera NS, Sato RT, Aragon-Alegro LC, Santana EHW. Avaliação físico-química e microbiológica do leite UHT comercializado em três países do Mercosul (Brasil, Argentina e Paraguai). Archivos Latinoamericanos de Nutrición [Internet]. 2010 Set [citado 29 jun 2015]; 60(3): 261-269. Disponível em: http://pesquisa.bvsalud.org/ses/resource/pt/lil-630326. Português.

13. Fischer V, Ribeiro MER, Zanela MB, Marques LT, Abreu AS, Machado SC, Fruscalso V, Barbosa RS, Stumpf MT. Leite instável não ácido: um problema solucionável? Revista Brasileira de Saúde e Produção Animal [Internet]. $2012 \mathrm{Jul} / \mathrm{set}$ [citado 29 jun 2015]; 13(3): 838-849. Disponível em: http://revistas.bvsvet.org.br/rbspa/article/view/12769/13607. Português.

14. Zanela MB, Fischer V, Ribeiro MER, Junior WS, Zanela C, Marques LT, Martins PRG. Qualidade do leite em sistemas de produção na região Sul do Rio Grande do Sul. Pesquisa Agropecuária Brasileira [Internet]. 2006 Jan [citado 29 jun 2015]; 41(1): 153-159. Disponível em: http://www.scielo.br/pdf/\%0D/pab/v41n1/28153.pdf. Português.

15. Marques LT, Fischer V, Zanella M, Ribeiro MER, Stumpf Junior W, Manzke N. Fornecimento de suplementos com diferentes níveis de energia e proteína para vacas Jersey e seus efeitos sobre a instabilidade do leite. Revista Brasileira de Zootecnia [Internet]. 2010 Dez [citado 29 jun 2015]; 39(12): 2724-2730. Disponível em: https://doi.org/10.1590/S1516-35982010001200024. Português.

16. Oliveira DS, Timm CD. Instabilidade da caseína em leite sem acidez adquirida. Revista Portuguesa de Ciências Veterinárias. 2007; 102(561-562):17-22.

17. Battaglini APP, Beloti V, Fagnani R, Tamanini R, Da Silva Dunga K. Caracterização físico-química e microbiológica do leite bovino instável não ácido em função das estações do ano. Revista Brasileira de Medicina Veterinária [Internet]. 2013 Jan/mar [citado 29 jun 2015]; 35(1): 26-32. Disponível em: http://www.rbmv.com.br/pdf_artigos/02-07-2013 11-00RBMV\%20007.pdf. Português.

18. Barchiesi-Ferrari CG, Williams-Salinas PA, Salvo-Garrido SI. Inestabilidad de la leche asociada a componentes lácteos y estacionalidad en vacas a pastoreo. Pesquisa Agropecuária Brasileira [Internet]. 2007 Dez [citado 29 jun 2015]; 42(12): 1785-1791. Disponível em: http://dx.doi.org/10.1590/S0100204X2007001200017. Espanhol.

19. O’Connell JE, Saracino P, Huppertz T, Uniake T, De Kruif CG, Kelly AL, Fox PF. Influence of ethanol on the rennet- induced coagulation of milk. Journal of Dairy Research [Internet]. 2006 Ago [citado 29 jun 2015]; 73(3): 312- 317. Disponível em: https://doi.org/10.1017/S0022029906001737. Inglês.

20. Baglinière F, Tanguy G, Jardin J, Matéos A, Briard V, Rousseau F, Robert B, Beaucher E, Humbert G, Dary A, Gaillard JL, Amiel C, Gaucheron F. Quantitative and qualitative variability of the caseinolytic potential of different strains of Pseudomonas fluorescens: Implications for the stability of casein micelles of UHT milks during their storage. Food chemistry [Internet]. 2012 Dez [citado 29 jun 2015]; 135(4): 2593-2603.

Cienc. anim. bras., Goiânia, v.19, 1-13, e-50399, 2018 
Disponível em: https://doi.org/10.1016/j.foodchem.2012.06.099. Inglês.

21. Silva NN, Piot M, Carvalho AF, Violleau F, Fameau AL, Gaucheron F. pH-induced demineralization of casein micelles modifies their physico-chemical and foaming properties. Food Hydrocolloids [Internet]. 2013 Ago [citado 29 jun 2015]; 32 (2): 322-330. Disponível em: https://doi.org/10.1016/j.foodhyd.2013.01.004. Inglês.

22. Fagnani R, Beloti V, Battaglini APP. Acid-base balance of dairy cows and its relationship with alcoholic stability and mineral composition of milk. Pesquisa Veterinária Brasileira [Internet]. 2014 Mai [citado 29 jun 2015]; 34 (5): 398-402. Disponível em: http://dx.doi.org/10.1590/S0100-736X2014000500002. Inglês.

23. Dias JA, Antes FG. Procedimentos para a coleta de amostras de leite para contagem de células somáticas, contagem bacteriana total e detecção de resíduos de antibiótico. Documentos / Embrapa Rondônia, ISSN 0103 9865; 150 [Internet]. Porto Velho, RO: Embrapa Rondônia, 2012 [citado 29 jun 2015]. Disponível em: https://www.infoteca.cnptia.embrapa.br/bitstream/doc/983813/1/doc150leite.pdf

24. IDF - International Dairy Federation 141C - Determination of milkfat, protein and lactose content Guidance on the operation of mid-infrared instruments. Brussels, Belgium, 2000. 15p.

25. Brasil. Ministério da Agricultura, Pecuária e Abastecimento. Instrução Normativa ${ }^{\circ} 68$, de 12 de dezembro de 2006. Diário Oficial da União. 2006 Dez 14. Português.

26. Salman AKD, Soares JPG, Canesin RC. Métodos de amostragem para avaliação quantitativa de pastagens. Circular Técnica 84 [Internet]. Porto Velho, RO: Embrapa Rondônia, 2006 [citado 29 jun 2015]. Disponível em: https://www.infoteca.cnptia.embrapa.br/infoteca/bitstream/doc/710690/1/ct84pastagem.pdf

27. Van Soest PJ, Robertson JB, Lewis BA. Methods for dietary fiber, neutral detergent fiber, and nonstarch polysaccharides in relation to animal nutrition. Journal of Dairy Science [Internet]. 1991 Out [citado 29 jun 2015]; 74 (10): 3583-3597. Disponível em: https://doi.org/10.3168/jds.S0022-0302(91)78551-2. Inglês.

28. Macedo Júnior GL, Zanine AM, Borges I, Pérez JRO. Qualidade da fibra para a dieta de ruminantes. Ciência Animal [Internet]. 2007 [citado 29 jun 2015]; 17 (6): 7-17. Disponível em: http://www.uece.br/cienciaanimal/dmdocuments/Artigo1.2007.1.pdf. Português.

29. Moreira PC, De Camargo Wascheck R, Dutra AR, Grandsire C, De Almeida OC. Influências Edafoclimáticas, Hormonais e Nutricionais na Produção de Vacas Leiteiras em Lactação. Estudos. 2008 Maio/jun [citado 29 jun 2015]; 35 (3): 481-500.

30. Oliveira CAF, Lopes LC, Rosim RE, Fernandes AM, Corassin CH. Composition, somatic cell count and casein fractions of ethanol unstable milks. Acta Scientiarum Technology [Internet]. $2013 \mathrm{Jan} / \mathrm{mar}$ [citado 29 jun 2015]; 35(1): 153-156. Disponível em: http://www.redalyc.org/html/3032/303226544022/. Inglês.

31. Ciprandi A, Pereira BP, Pinto AT. Ocorrência de leite instável não ácido (LINA) em uma usina de beneficiamento da região metropolitana de Porto Alegre/RS. Veterinária em Foco [Internet]. 2012 Jan/jun [citado 29 jun 2015]; 9(2): 128-133. Disponível em: http://revistas.bvsvet.org.br/vetfoco/article/view/26364/27412. Português.

32. Werncke D. Perfil das propriedades e ocorrência de leite instável não ácido na região do vale do braço do norte, sul do Estado de Santa Catarina. Lages. Dissertação [Mestrado em Ciência Animal] - Centro de Ciências Agroveterinárias da Universidade do estado de Santa Catarina, 2012. Disponível em: http://tede.udesc.br/handle/handle/796

33. Nero LA, Viçosa GN, Pereira FEV. Qualidade microbiológica do leite determinada por características de produção. Ciência e Tecnologia de Alimentos [Internet]. 2009 Abr./jun. [citado 29 jun 2015]; 29(2): 386-390. Disponível em: http://www.redalyc.org/html/3959/395940092024/. Português.

34. Gerdes L, Werner JC, Colozza MT, Possenti RA, Schammass EA. Avaliação de características de valor nutritivo das gramíneas forrageiras Marandu, Setária e Tanzânia nas estações do ano. Revista Brasileira de Zootecnia [Internet]. 2000 [citado 29 jun 2015]; 29(4): 955-963. Disponível em: 
http://www.scielo.br/pdf/rbz/v29n4/5606. Português.

35. Alessio DRM, Thaler Neto A, Velho JP, Perreira IP, Miquelluti DJ, Knob DA, Silva CG. Multivariate analysis of lactose content in milk of Holstein and Jersey cows. Semina: Ciências agrárias [Internet]. 2016 [citado 27 jan 2017]; 37 (4): 2641-2652. Disponível em: http://dx.doi.org/10.5433/16790359.2016v37n4Supl1p2641. Inglês.

36. Figueiroa FJF, De Marchi FE, Santos GTD, Santos WBRD, Kazama DCS, Leite LC, Branco AF, Damasceno JC. Production, composition and fatty acid profile of milk and butter texture of dairy cows fed ground or pelleted concentrate with sunflower and/or lignosulfonate. Revista Brasileira de Zootecnia [Internet]. 2013 Out [citado 29 jun 2015]; 42(10): 743-750. Disponível em: http://dx.doi.org/10.1590/S151635982013001000008. Inglês.

37. Schmidt FA. Efeito do suprimento das exigências de energia e/ou proteína na recuperação da instabilidade do leite ao teste do álcool. Lages. Dissertação [Mestrado em Ciência Animal] - Centro de Ciências Agroveterinárias da Universidade do estado de Santa Catarina, 2014. Disponível em: http://tede.udesc.br/handle/handle/929

38. Smith R, Moreira L, Latrille L. Caracterización de sistemas productivos lecheros en la X región de Chile mediante análisis multivariable. Agricultura Técnica [Internet]. 2002 Jul [citado 29 jun 2015]; 62(3): 375-395. Disponível em: http://dx.doi.org/10.4067/S0365-28072002000300004 . Espanhol.

39. Gabbi AM, Mcmanus CM, Silva AV, Marques LT, Zanela MB, Stumpf MP, Fischer V. Typology and physical-chemical characterization of bovine milk produced with different productions strategies. Agricultural Systems [Internet]. 2013 Out [citado 29 jun 2015]; 121(1): 130-134. Disponível em: https://doi.org/10.1016/j.agsy.2013.07.004. Inglês.

40. Werncke, D.; Gabbi, A. M.; Abreu, A. S.; Felipus, N. C. Machado NL, Cardoso LL, Schmid FA, Alessio DRM, Fischer V, Thaler Neto A. Qualidade do leite e perfil das propriedades leiteiras no Sul de Santa Catarina: abordagem multivariada. Arquivo Brasileiro de Medicina Veterinária e Zootecnia [Internet]. 2016 Mar/abr [citado 27 jan 2017]; 68(2): 506-516. Disponível em: https://doi.org/10.1590/1678-4162-8396. Português. 